\title{
Personnel imbalance and ways to overcome it in the healthcare sector
}

\author{
Eleonora Chernenko ${ }^{1, *}$, and Inna Lebedeva ${ }^{2}$ \\ ${ }^{1}$ Kuban State Technological University, Krasnodar, Russia \\ ${ }^{2}$ Kuban State Medical University, Krasnodar, Russia
}

\begin{abstract}
The National Healthcare Project, which has been implemented in our country since 2019, includes eight federal projects aimed at developing individual elements of the industry. The federal project "Providing medical organizations of the healthcare system with qualified personnel" is the connecting link of all eight projects. It involves the elimination of the shortage of doctors and nurses in polyclinics, the staffing of medical workers by $95 \%$ and an increase in the number of doctors by $10 \%$ by the end of 2024 . Without a sufficient number of specialists in the industry, its effective work is impossible. The surge in the incidence of coronavirus infection has become another challenge for the healthcare industry and exacerbated the problem of staff shortages. To solve the personnel problem, first of all, it is necessary to understand the reasons for the imbalance, to understand the incentives of young people who have just come to receive education and in the labor motives and doctors already working in the industry, to know the reasons that force them to leave the profession. The article presents the results of a study of factors-motivators of medical students, as well as medical workers.
\end{abstract}

\section{Introduction}

The federal project "Providing medical organizations of the healthcare system with qualified personnel" is not just one of eight federal projects, it is the basis for the implementation of the rest. This federal project involves solving a wide range of issues, including improving the work of educational organizations that train healthcare professionals, increasing the efficiency of their employment, and measures of social support.

External factors make adjustments to the plans and opportunities for the implementation of industry development programs, including federal projects, united by the national project "Healthcare". So, in March 2020, the surge in the incidence of coronavirus infection necessitated an urgent update of data on all available healthcare resources for their further planning and effective use, and, first of all, data on the number of medical personnel. For this, an urgent registration of all Russian doctors and nurses was carried out in the unified state information system in the field of health care and the mobilization of all industry resources. [1]

\footnotetext{
* Corresponding author: 79184814276@yandex.ru
} 
On February 26, 2021, ONF experts held a round table on the implementation of the Healthcare national project. Deputy Minister T.V. Semenova said that a 120,000 shortage of nurses was recorded (today the industry employs 1.3 million). The average outflow and internal migration is within $6-8 \%$. The volume of inflow to the industry this year is 66 thousand people, next year - about 72 thousand people, and the maximum output in 2022 will be 77 thousand specialists. The capacity of training specialists must be at least doubled. The discussion of the new generation federal state educational standard for the training of nurses is already coming to an end, where the standard training time is reduced from the original by 8 months.

According to Rosstat data, at the end of 2018, the number of doctors in our country was 703.7 thousand people, and the number of nurses was 1491.4 thousand people, which is 47.9 and 101.6 for 10,000 people, respectively. Compared to 2010 , the indicator decreased by 2.2 and 4.0, respectively. [2]

According to Rosstat, at the end of 2018, 50 thousand vacancies for doctors and nurses remained open. The greatest shortage of personnel was in the Kamchatka Territory (20\%) and the Smolensk Region (2.7 thousand rates - 18\%). In 2019, the shortage of doctors here was 537 people $(12.8 \%)$, nurses - 805 people (10.2\%). In the Pskov region (third place), the number of vacancies almost halved from 2.3 thousand in 2018 to a thousand places in 2019 . Regional ministries provide social support measures for doctors, as well as students and residents who have concluded contracts for targeted training, doctors attracted under the program "Zemsky Doctor", but these measures are not enough. [3, 4]

The construction of professionalism and the choice of career strategy depend on whether the doctor intends to continue working in one place or prefers to change places of work. The most significant motivation for working in rural areas is the ability to communicate with patients for a long time, to play the role of the keeper of the local space. An additional incentive is the benefits that are provided to participants in the state program "Zemsky Doctor". [5, 6]

As of January 1, 2020, 5,677,786 residents lived in the Krasnodar Territory, the number of doctors - 18,567 people, nursing staff - 39,011 people. The provision of the population with doctors is 32.7 per 10,000 people. - below the national average (37.4) with low provision of the population with paramedical personnel -68.7 per 10,000 people. The ratio of the number of doctors and nurses is $1: 2.1$.

According to the Rector of the Higher School of Organization and Management of Healthcare G.E. Ulumbekova, in the regions the shortage of doctors in the areas is 37 thousand people, nursing staff - 66 thousand people. (need 149 thousand), medical assistants - 20 thousand people, medical specialists - 30 thousand people. According to the Order of the Ministry of Health and Social Development of the Russian Federation of 15.05.2012, No. 543n, the recommended number of the attached adult population is: at the medical assistant's area - 1300 people, at the therapeutic area - 1700 people. (for rural areas - 1300 people), at the site of a general practitioner - 1200 people, at the site of a family doctor - 1500 people, at a complex site - 2000 and more. Inconsistency of the standard with the fact (doctors are forced to serve a site of 3 thousand people) Ulumbekova considers "problem number one" in Russian medicine. According to the expert, the reasons for this are low salaries and a large amount of work associated not with medical activities, but with paperwork. [4]

In his message to the Federal Assembly, the President of the Russian Federation called the issue of attracting personnel a key issue for Russian medicine. To solve it, it is planned to provide specialists at all levels of health care by 2024, including by increasing the share of targeted budget places and introducing a new remuneration system with the establishment of a fixed share of salaries in wages and a unified list of compensation payments and incentive bonuses. [7] 


\section{Materials and methods for studying motivation}

According to the requirements of the Federal State Educational Standard of Higher Education, a graduate of a medical university must be ready to carry out professional activities and have a set of competencies corresponding to his specialty. Mastering them in the learning process is impossible without students' motives for acquiring this knowledge, abilities and skills.

Previously, there was an opinion that medical students become in two cases: the first "doctor from God" when the entrant really has a talent for medicine, and the second - to continue the dynasty, when the traditions and values laid in the family determined the future profession. Both of these options certainly have a rational grain. First, it is impossible to instill a love of medicine to someone who does not want to do it. And secondly, it is human nature to imitate. The child, imitating parents, adopts their experience and basic skills, formed involvement in the profession, which provides further selfdevelopment and self-realization.

Today, when the practice of compulsory employment of graduates that existed in the Soviet system is no longer applied, the intensifying competition among them for a better and more highly paid job leads to the fact that practically throughout the country there is not only a shortage, but also an outflow of medical personnel.

Understanding what is a priority, what affects the motivation of applicants, students, graduates, doctors with experience - means to understand the very reason for the shortage of personnel.

The medical profession did not gain popularity overnight. Initially, only men could be doctors, and most often they were dynasties of doctors. The system of medical education gradually developed, it became available to everyone who has the ability and desire to practice medicine. Talent and the continuation of the dynasty (family traditions) were the determining factors. Later, the desire to practice medicine began to be influenced by the possibility of good earnings. For example, it is a known historical fact that in his youth A.P. Chekhov did not even dare to think about devoting his life to literary activity. Poverty and concern for his family forced him to choose medicine, which at that time brought substantial income and allowed him to break out "into the people." Today, the factor of the prestige of the profession and good earnings is the main factor in choosing a future profession, and for schoolchildren in graduating classes it does not testify in favor of medicine. In the fall of 2020, a survey was conducted through Google Forms among 1st year students of Kuban State Medical University. The number of respondents is 167 people. The number of questions in the questionnaire - 10. The questionnaire was compiled on the basis of the methodology of A.P. Vasilkova, who modified the test of motives of study by V. Henning.

Theories of motivation have been considered by many scientists: A. Maslow, F. Herzberg, D. McClelland, L. Porter, E. Lawler, E.P. Ilyin and many others, each in his own way trying to find "... a rational grain that reflects one of the sides of the motive as the basis of action, deed, activity, behavior." Of greatest interest for our research is the identification of types of motives for educational activities in accordance with the value claims according to Hening. The need, on the one hand, and the intention to do something, including the urge to do this, on the other, are the boundaries of the motive, and the motive itself is orienting in the means of inducing to realize the claims. [8,9]

The questionnaire was compiled using the modified method of W. Henning. The respondents answered the question "What prompted you to choose a medical specialty?", Assigning 1 to 3 points for each of the 9 statements. In terms of importance, the motives were distributed in the following sequence: the ability to take care of the health of their loved ones $(90.4 \%)$, the desire to alleviate the suffering of seriously ill patients, the elderly, 
children $(77.8 \%)$, the desire to treat people $(73.3 \%)$, the ability to take care of their own health $(63.5 \%)$, desire to solve scientific medical problems $(38.8 \%)$, the ability to influence other people (34.9\%), material interest $(27.1 \%)$. Thus, at the initial stage, future specialists are driven by the basic needs identified by A. Maslow (safety, security) with a characteristic social orientation. This largely explains the current situation when students (especially girls), having received knowledge, use it to treat close relatives, children, in fact, leaving the profession.

The motive, which was decisive at the stage of the formation of medicine, today turned out to be the last in the list - the prestige of the profession and family traditions were chosen by $9.1 \%$. Young people, becoming students of a medical university just so as not to upset their parents, in the future do not feel the desire to overcome the difficulties that first appeared in their studies, and having received a diploma, they do not want to remain in the profession. Therefore, it is important, even at the stage of choosing a university for admission, to understand and answer for yourself the question "Do I want to practice medicine?" If the continuation of the dynasty is a deliberate choice, then this factor, on the contrary, is basic in motivation, and it is this factor that forms aspirations and desires. A student comes to receive knowledge at a university already morally ready to work in this profession.

Later, when students have a desire and opportunity to start earning, or when the financial support of parents becomes noticeably less, in relation to needs, the factor - "the size of wages" becomes more and more important, in this regard, students begin to choose more carefully future specialization and take into account not only interest in it, but also material support, prestige and ease of employment.

For students just starting their studies, social orientation is basic. In an unstable epidemiological situation, the ability to take care of one's own health and the health of loved ones is becoming increasingly important.

Human health, which is one of the main elements of the national security of the country, in our case is the main object of the professional activity of a doctor. The society makes ever higher demands on the efficiency of the work of medical personnel. It, in turn, depends not only on professionalism, but also on the motivation of specialists.

The results of a survey conducted last year among senior students of higher and secondary medical educational institutions showed that $58.5 \%$ of respondents had an interest in the medical profession in choosing to become a doctor, $17.5 \%$ - the prospect of good earnings after graduation. $9.9 \%$ had a desire to continue the medical dynasty, $6.6 \%$ had an urgent recommendation from their parents. The older and more independent the respondents are, the more the factor of material needs (earnings) comes to the fore. It is logical to assume that this factor will dominate among people who have already started their professional activities.

\section{Analysis of factors motivating the labor activity of medical workers}

The basis of meaningful theories of motivation is the analysis of human needs, and the main emphasis is on determining their structure. However, this hierarchical structure is not absolutely rigid, since the true motives of human behavior are complex and not always available for understanding, incl. and by the individual.

So Yu.A. Izoteev, head of the surgery department of the City Clinical Hospital No. 1 of Nizhny Tagil, reporting on the reasons for the mass dismissal of doctors, explained: "Salary is not the most important thing, this is not the first requirement. Our main condition is staffing, improvement of round-the-clock diagnostics and legal protection of the doctor before the patient and his relatives ". 
Of greatest interest in health care management is the theory of motivation by $\mathrm{F}$. Herzberg, who singled out two groups of factors that are different in nature: those associated with the nature and essence of labor activity itself (career growth; recognition of merits; remuneration associated with work results; a high degree of responsibility), i.e. e. motivating factors and factors that keep at work, shaping the working environment (convenient work schedule, sanitary and hygienic conditions, workplace comfort, absence of unnecessary stress); the amount of earnings and the availability of material benefits; interpersonal relationships in a team.

Among the surveyed senior students, $69 \%$ would like to work in a private clinic after graduation. At the same time, "I agree" in the affirmative to the question "If you are offered to work in rural areas after graduation, what will you answer?" answered $12.8 \%$. Interestingly, 57\% would agree under certain conditions. Among the weighty reasons for working in rural areas, $46.8 \%$ of respondents named high wages, $20.5 \%$ - an equipped workplace and a medical institution that meets modern requirements, $8.8 \%$ - social infrastructure equivalent to urban.

The limited financial resources with an increase in the average age of medical personnel (over 45 years) makes it necessary to take into account the effectiveness of employee motivation. Ideally, healthcare providers should be able to maximize the satisfaction of their needs, which will enable them to develop themselves and expand the capabilities of institutions. Motivation to improve professional skills is a necessary tool for human resource management. However, in healthcare there is a factor of professional burnout and a significant decrease in the need for professional growth by the middle of labor activity.

In the message of the President to the Federal Assembly, it was noted that this year, in accordance with the national project "Health", the deployment of a network of feldsherobstetric centers will be completed, from July 1, a program for the modernization of primary health care will be launched, which involves the construction, repair and equipment of medical institutions in settlements up to 50 thousand people. According to the Ministry of Health of the Russian Federation, from 2021 to 2023, 90 billion rubles will be allocated; more than 3 thousand medical organizations have already joined the program of modernization of the primary care; all regions on December 15 approved their programs, financial resources are included in the budget of the Russian Federation. In the Krasnodar Territory, the Head of the Administration (Governor) also signed the Order No. 323-r "On the approval of the regional program of the Krasnodar Territory" Modernization of primary health care ". Its total budget for 2021-2025. is 20,273.3 million rubles, of which: federal budget funds 19,216.1 million rubles. and funds of the regional budget 1057.2 million rubles.

A lot of attention is now being paid to finding opportunities to overcome the talent shortage in the industry, including expanding the opportunities for reception by general practitioners (GPs) and family doctors. It is interesting that such attempts were made back in the late 1980s. In 1992, the Order of the Ministry of Health of the Russian Federation No. 237 "On a phased transition to the organization of primary health care according to the principle of a general practitioner (family doctor)" stated that in order to accelerate reforms in health care, adapt the industry to the conditions of a market economy introduction of new principles for the provision of primary health care to the population, the basis of which is a general practitioner (family doctor).

In countries included in the lists of the most effective health systems (according to various analytical agencies: WHO, InsuranceGuru, Lancet, Bloomberg, Legatum Institute, Numbeo), the experience of GPs is widespread - 80-90\% of medical problems are solved at the primary level (Great Britain, Canada and etc.). In Russia, at the moment, only $40 \%$ are solved. [11] 
Attempts to implement this direction began in a number of regions of our country - the Chuvash Republic, Penza and Voronezh regions, etc. period until 2020 ", where in the part" Development of health care ", among the measures aimed at improving the efficiency of the system of organizing medical care, the opening of offices of general practitioners and family doctors in rural areas was noted.

An analysis of the data for the Krasnodar Territory for 10 years revealed that, on average, there are 1219 people per one GP (total 198 GPs) in the Krasnodar Territory. attached population. However, in $26.8 \%$ of general practitioners, the volume of the attached population in the areas exceeds the recommended values by 1.5 times or more. More than 100,000 adults in the region are served under conditions of excessive workload on general practitioners. It is also worth noting the considerable age of specialists in the GP system, which is 50 years old, more than $25 \%$ of currently working GPs are working pensioners by the age criterion. The indicator is forecast to grow up to $50 \%$ in the medium term. The need for personnel in the GP system, taking into account those who have reached retirement age, is 146 doctors. [12]

When analyzing the data of the consolidated form of state statistical observation No. 30 "Information about the medical organization" for medical organizations of the Krasnodar Territory in 2019, out of 18567 doctors (individuals), 4550 people had the highest qualification category. (24.5\%), the first - 2088 people. (11.2\%), the second - $739(3.9 \%)$. In 2015, out of 18088 doctors (individuals), 3713 people had the highest qualification category. (20.5\%), the first - 1466 people. $(8.1 \%), 845-739$ (4.7\%). The increase in the share of people with the highest qualification category, while the share of people with the first qualification category is decreasing, suggests that only old cadres improved their qualifications, while newcomers to the industry are not motivated to develop professional skills.

According to the WHO recommendations (Munich Declaration of WHO, June 2000), the ratio of the number of doctors and nurses should be 1: 4. On average, in foreign countries this ratio is $1: 3$, in Russia - 1: 2.2. In rural areas, 54.4 thousand doctors $(10 \%$ of all doctors) and 196.5 thousand ambulances (16.0\% of the total ambulance) are employed. Eliminating the staff shortage and leveling the imbalance today is given special attention by the government.

In order to study the prospects of higher nursing education on the example of medical educational institutions in Krasnodar. We conducted a study by questioning graduate students of the Krasnodar Regional Basic Medical College and the Krasnodar Municipal Medical Institute of Higher Nursing Education (172 respondents).

Most of the respondents $(69 \%)$ after graduating from an educational institution want to work in a private clinic, $19.9 \%$ are ready to work in a state one, $5.8 \%$ want to work in a research organization, and $5.3 \%$ want to work in a medical university. It is interesting that at the moment more than $25 \%$ of the teaching staff of the Krasnodar Regional Basic Medical College are its graduates and, as can be seen from the survey, the willingness to work in the educational environment was also noted among the respondents.

As a result of a survey of students studying in the direction of "nursing" in the GNS system, it was revealed that most of the respondents $(71.6 \%)$ after completing their studies want to stay in the specialty and continue to work in medical organizations, every tenth $(12.5 \%)$ is going to work in healthcare management bodies, $5.5 \%$ of the respondents want to work in professional educational institutions. However, $9.2 \%$ of graduate students do not plan to work in their specialty.

To the question "What influenced your choice of specialty?" $63.4 \%$ of all respondents answered that the chosen specialty is the most interesting for them, $18 \%$ noted the prestige of the specialty, $9.3 \%$ admitted that parents insisted on choosing a specialty, and for $8.7 \%$ the choice of a specialty is due to guaranteed employment in the future. 
To the question "If you had the opportunity to change your profession to any other, would you use this opportunity?" $12.8 \%$ of respondents answered in the affirmative, $29.7 \%$ found it difficult to answer, $57.6 \%$ would not like to change their profession.

Analysis of literary sources and the opinions of respondents showed that both the graduates of the faculties of the GNS and the heads of medical institutions consider unclaimed specialists in the specialty "Nursing" with the qualifications of a manager or a managing nurse, which forces graduates of this specialty to agree to employment for a lower position that does not require a higher education.

Nursing education is most popular among women (73.8\% of respondents). Most of them are interested in the chosen specialty. However, readiness for further employment is influenced by a number of factors, among which the employment prospects dominate. Based on the data obtained, it can be concluded that almost a quarter of graduates are already ready or are going (while hesitating in their decision) to change their profession. Graduates note the low demand for higher nursing education. In general, we can talk about great prospects for secondary vocational education.

The above-mentioned problems of providing the healthcare industry with medical personnel can be solved through the implementation of the national project "Healthcare" and federal programs. However, in our opinion, the pandemic both raised the status of medical workers and opened up to society all the hardships of medical work in a difficult epidemiological situation. A new look at the difficult work of doctors can influence the final decision and alienate applicants who are still choosing their future profession and hesitate in their decision to become a medical worker (doctor, paramedic, nurse), but at the same time attract those who are ready to sacrifice themselves for a good purpose " Serving people. " Such a desire needs to be developed and stimulated, and this requires a clear example of a person who has devoted himself to the profession in the field of medicine. In our opinion, the institution of mentoring, which already exists in many areas of the economy, is simply necessary in health care. As mentioned above, a relative mentor in the dynasties of health care workers is a wonderful example of the transfer of experience, knowledge and skills. However, it is more difficult for non-medical students to find a mentor who is willing to share experience and knowledge.

The President of the Russian Federation also spoke about the need to create an institute of mentoring in health care during a meeting with university students on the Day of Russian Students, in his words, mentoring should be financially stimulated. Currently, the projects "Guidelines for the organization of mentoring in health care institutions" and activities for the formation of a mentoring system in health care institutions of the Russian Federation are being implemented, which involve mentoring young specialists within two years after employment.

In our opinion, mentoring for five years (for doctors and paramedics) and 2 years (for nursing staff) is optimal, while alternative options for material incentives should be offered: providing a more gentle work schedule, additional vacation days, pension supplements, etc. Mentors should be mainly employees who have reached pre-retirement age (in the case of medical workers, these are persons with more than 25 years of professional experience); persons in leadership positions in health care, as well as medical practitioners, paramedics and nursing staff.

In addition to the institute of mentoring, it is necessary to carry out career guidance work among graduating classes and applicants, in order to form a personnel reserve in health care. In our opinion, in addition to specialized lyceums, gymnasiums and schools, it is necessary to pay attention to graduates of orphanages and boarding schools, who are often not guided by anything in choosing a profession. This category of applicants should be given more attention in vocational guidance work, as well as in the provision of social support measures, which will be a stimulating factor in choosing a medical specialty. 
These measures, together with the measures envisaged for the development and modernization of the healthcare sector, will reduce the staff shortage and increase the attractiveness of the medical profession.

\section{Conclusions}

1. The surge in the incidence of coronavirus infection has necessitated an urgent update of data on the health workforce for their effective use. Today there is a significant shortage of personnel, a decrease in their inflow is recorded, the ratio of the number of doctors and nurses does not correspond to the recommended values.

2. At the initial stage, students of medical schools are driven by basic needs (safety, security) with a characteristic social orientation, which largely explains the application of the knowledge gained to treat close relatives and leave the profession in the future. For senior students, the opportunity to earn money comes to the fore. They choose their future specialization more carefully and take into account not only interest in it, but also material support, prestige and ease of employment.

3. For those already working in the industry, the priority is working conditions, the amount of earnings, the availability of material benefits, interpersonal relationships in the team. Motivation to work in the middle of a career is significantly reduced. There is a factor of "professional burnout".

4. To overcome the personnel imbalance in the industry, it is necessary to use a set of planned and implemented measures, taking into account the influence of factors motivating labor activity. As well as the use of mentoring experience and focus on measures of social support for both applicants and already working specialists.

\section{References}

1. N.A. Avxentyev, V.S. Nazarov, N.N. Sisigina, Economics questions, 6, 22 (2020)

2. E.M. Chernenko, I.S. Lebedeva, E.A. Gorlova E.A., 2nd International Scientific and Practical Conference on Digital Economy (ISCDE 2020), Trends in the use of Digital Technologies in the Decision of the Personnel (2020)

3. Healthcare in Russia (Stat.sb.Rosstat, 2019)

4. D. Lindell D., E. Kuznecova, Rosstat named the regions with the greatest shortage of doctors, https://www.rbc.ru/

5. K. Galkin, World of Russia, 29(3), 142 (2020)

6. K. Galkin, The Journal of Social Policy Studies, 18(2), 175 (2020)

7. Presidential Address to the Federal Assembly (Moscow, 2020), http://en.kremlin.ru/

8. Hennig Werner. Lernmotive bei Schülern. (Psychologische Beiträge. Heft 23) (Volk und Wissen Volkseigener Verlag, 1978)

9. A.P Vasilkova, Method: Motivation for choosing a medical profession, https://www.sites.google.com/

10. WHO, Global strategy on human resources for health: workforce 2030, 64 (2016) https://apps.who.int/

11. I.A. Dzhioeva, L.A. Gadzhieva, The Journal of scientific articles "Health and Education Millennium", 18(1), 194 (2016)

12. S.N. Alekseenko, A.N. Redko, V.R. Khan, I.S. Lebedeva, Kuban Scientific Medical Bulletin, 27(2), 18 (2020) 